\title{
Study of effects on power system relay protection by harmonic and negative sequence components of electrified rails
}

\author{
Jia Liu ${ }^{1}$, Tao Lin $^{2}$, Xing Xian ${ }^{1}$, Qing Gong ${ }^{1}$ and Fuzhang Wu ${ }^{2, a}$ \\ ${ }^{1}$ Hubei Electric Power Survey \& Design Institute, Wuhan 430024, Hubei Province, China \\ ${ }^{2}$ School of Electrical Engineering, Wuhan University, Wuhan 430072, Hubei Province, China
}

\begin{abstract}
The traction power supply system of electrified railway will cause harmonic and negative sequence current when connecting to the common power net. The propagation characteristics of harmonic and negative sequence current are studied by analyzing a certain power network in the ETAP software, and then the effects on the actions of power relay protection including line protection, bus protection, transformer protection and generator protection by the propagation characteristics are studied, which provides references for the power grid planning.

Keywords: electrified railway; harmonic; negative sequence current; relay protection; ETAP; power grid planning.
\end{abstract}

\section{Introduction}

In recent years, the rapid development of our country's economy and the continuous improvement of large demand of the living standard have been promoting the rapid development of electrified railway in our country, in addition, electrified railway is considered to be the most ideal way of transportation right now because of its characteristics such as high efficiency, energy saving and environmental protection, thus the electrification of the railways have become a key project of our country's railway planning and it has become the inevitable trend of power system development that mass of electrified railway loads connect to the power grid. However, electric locomotive with traction power system which converts three-phase current to single-phase current accesses power makes himself a single-phase unbalanced load different from traditional three-phase loads. so, electric locomotives are easy to produce power quality problems such as harmonic and negative sequence current, which not only have detrimental effects on traction power system and the superior power system but also result in unreliable actions of the original protection and finally reduce the economy and stability of the whole power system.

Currently, the power quality and relay protection problems brought by electrified railways have become a hot topic of research at home and abroad. That the mass of electrified railways connect to the common power net will cause harmonic and negative sequence current and may affect the actions of relay protections [1-5]. The paper[6,7] mainly study the effects on line protection by the power quality brought by electrified railways. The paper[8-10] mainly study the effects on generator

a Corresponding author : 506653926@qq.com

(C) 2016. The authors - Published by Atlantis Press 
protection by the negative current. Whereas, there have little studies of the effects on bus protection and transformer protection by the harmonic and negative sequence current caused by electrified railways.

The propagation characteristics of the harmonic and negative sequence current due to the connection of electrified railways in the common power net and their effects on protection for transmission lines, buses, transformers and generators are studied by analyzing a certain power network in the ETAP software, which provides guidance for the power grid planning.

\section{Study of the propagation characteristics of harmonic and negative sequence components caused by electrified railways in the common power net}

\subsection{Modeling of the algorithm}

Model the modeling of a certain power network in the ETAP software. The power network includes six areas connected by $110 \mathrm{kV}$ lines, the high-speed rails powered by the substations of no. 1 area through $220 \mathrm{kV}$ lines and the subway powered by the substations of no.4 area through $10 \mathrm{kV}$ lines. There have two generators in the no.6 area.

\subsection{Modeling of the harmonic and negative sequence current sources in the ETAP}

\subsubsection{Modeling of the harmonic source}

The actual value of each harmonic current injected to the transmission lines of traction substations by the electrified railway must be measured first, and then:

(1) Use the load models equivalent the electrified railway loads in ETAP according to the measured size of electrified railway loads;

(2) Input the measured value of each harmonic current of electrified railway loads into the harmonic source library of the load models and use harmonic current sources simulate harmonic current loads.

\subsubsection{Modeling of the negative sequence current source}

The electrified railway load is an unbalanced three-phase load from the system side. The simulation uses the unbalanced power flow module of ETAP software. Because the three-phase active power and reactive power rather than the negative sequence current can be measured, when modeling the negative sequence current source, input the single-phase load into the ETAP directly. Through the above steps, modeling can be completed.

\subsection{Harmonic power flow analysis}

Because most of harmonic sources are current sources and the harmonic current is the emphasis, current balance equations are used in harmonic power flow analysis[11]. Generally, the harmonic bus admittance matrix $Y_{h}$ is applied to describe the connection of harmonic net and the branch harmonic admittance, the equation of harmonic net is shown as follows.

$$
\dot{I}_{h}=Y_{h} U_{h}
$$

$\dot{I}_{h}$ is the column vector of harmonic current; $\dot{U}_{h}$ is the column vector of harmonic voltage of 
nods. The fundamental current and harmonic current of the fundamental sources are shown in the formulas (2) and (3).

$$
\begin{gathered}
I_{1}=g_{1}\left(U_{1}\right) \\
I_{n}=g_{n}\left(U_{1}, U_{2}, \cdots\right), n=2,3 \cdots
\end{gathered}
$$

Iterate compute the formulas (2) and (3) until the results meet the convergence accuracy, the harmonic power flow analysis can be completed[12].

\subsection{The propagation characteristics of the power quality caused by electrified rails}

After modeling the harmonic and negative sequence current sources in the ETAP, the harmonic, the negative sequence current and voltage of lines, buses and generators can be calculate respectively, and the results will be used to study the effects on the criterion of starting of protection for lines, the second harmonic escapement criteria of protection for transformers, bus differential protection and the negative sequence overload criterion of protection for generators.

The negative sequence current of each line in the system is obtained by simulation, and the results are shown in Table 1.

The negative sequence voltage of each bus is shown in table 2.

According to the characteristics of the inrush current of three-phase transformer, the second harmonic escapement is usually adopted to prevent the malfunction of the longitudinal differential protection caused by the inrush current. Thus it is crucial to obtain the second harmonic current when there have faults. The transformer of no.1 area closest to the electrified railway traction station was selected as the research object to analyze the second harmonic current of the differential current of fault phase when there is a fault on the transformer high pressure side and low pressure side.

Table 1. The negative sequence current of each line

\begin{tabular}{cc}
\hline Name of line & $\begin{array}{c}\text { The negative sequence current } \\
\text { (A) }\end{array}$ \\
\hline Line of no.3-no.7 area & 1.7 \\
Line of no.3-no.4 area & 1.9 \\
Line of no.6-no.7 area & 1.22 \\
no.1 Line and no.2 line of no.1-no.3 area & 1.86 \\
no.1 Line and no.2 line of no.1-no.2 area & 1.12 \\
no.1 line and no.2 Line of no.1-no.5 area & 1.4 \\
\hline
\end{tabular}

Table 2. The negative sequence voltage of each bus

\begin{tabular}{ccc}
\hline Name of bus & $\begin{array}{c}\text { Magnitude of the Negative voltage } \\
(\mathrm{kV})\end{array}$ & $\begin{array}{c}\text { The percentages of the } \\
\text { Magnitude of the Negative } \\
\text { voltage }(\%)\end{array}$ \\
\hline no.6 area $10 \mathrm{kV}$ & $4.90 \mathrm{E}-03$ & 0.049 \\
no.6 area $110 \mathrm{kV}$ & 0.13 & 0.12 \\
no.3 area $10 \mathrm{kV}$ & $6.44 \mathrm{E}-03$ & 0.064 \\
no.3 area $110 \mathrm{kV}$ & 0.13 & 0.12 \\
no.7 area $10 \mathrm{kV}$ & $6.20 \mathrm{E}-03$ & 0.0641 \\
no.7 area $110 \mathrm{kV}$ & 0.12 & 0.1205 \\
no. 2 area $10 \mathrm{kV}$ & $1.20 \mathrm{E}-02$ & 0.1195 \\
no.2 area $110 \mathrm{kV}$ & $7.10 \mathrm{E}-02$ & 0.0649 \\
no.5 area $10 \mathrm{kV}$ & $6.41 \mathrm{E}-03$ & 0.0641 \\
no.5 area $110 \mathrm{kV}$ & $7.13 \mathrm{E}-02$ & 0.064 \\
no. 1 area $10 \mathrm{kV}$ & $6.49 \mathrm{E}-03$ & 0.0649 \\
no. 1 area $110 \mathrm{kV}$ & 0.143 & 0.13 \\
\hline
\end{tabular}


Different types of faults are set at the outlet of the high voltage side of transformers, and the second harmonic current of the fault phase of transformers is shown in table 3.

Table 3. The second harmonic current of the fault phase, when different types of faults are set at the outlet of the high voltage side of transformers

\begin{tabular}{cc}
\hline Types of faults & The second harmonic current \% \\
\hline Three-phase fault & 2.13 \\
Two-phase ungrounded short-circuit & 2.07 \\
Two-phase grounded short-circuit & 2.01 \\
Single-phase grounded short-circuit & 1.98 \\
\hline
\end{tabular}

Different types of faults are set at the outlet of the low voltage side of transformers, and the second harmonic current of the fault phase of transformers is shown in table4.

Table 4. The second harmonic current of the fault phase, when different types of faults are set at the outlet of the low voltage side of transformers

\begin{tabular}{cc}
\hline Types of faults & The second harmonic current \% \\
\hline Three-phase fault & 2.24 \\
Two-phase ungrounded short-circuit & 2.17 \\
Two-phase grounded short-circuit & 2.16 \\
Single-phase grounded short-circuit & 2.02 \\
\hline
\end{tabular}

Calculate the negative sequence current of the two generators in the no. 6 area as shown in table 5 .

Table 5. The negative sequence current of the two generators end in the no.6 area

\begin{tabular}{cc}
\hline Name of generator & Negative sequence current \\
no.1 generator of no.6 area & $6.6 \mathrm{~A}$ \\
no.2 generator of no.6 area & $7.1 \mathrm{~A}$ \\
\hline
\end{tabular}

\section{Study of effects on the actions of relay protection by the harmonic and negative sequence components in the common power net}

In order to analyze the influence on the actions of relay protection by electrified rails, the propagation characteristics of power quality caused by electrified rails in the common power net are studied, and then compared with the criterion's setting values related with harmonic and negative sequence current of existing protection for lines, transformers, generators.

\subsection{Study of effects on line protection}

\subsubsection{Effects on the line protection by harmonic current}

All the areas in the model are connected by $110 \mathrm{kV}$ lines which install diverse protection starting elements. Because computer protections are used commonly in line protection and computer protections have matured with fine filtering characteristics, such as the full-cycle fourier algorithm can remove all of integer harmonics and the continuous complex-wavelet transform is able to filter the integer and noninteger harmonic, there has no effects on line protection by the harmonic.

\subsubsection{Effects on the line protection by the negative sequence current}

The negative sequence current primarily influences the negative sequence current protective starting elements. According to the relay protection setting notice of each line and compare the setting values 
with calculated values, the result of effects on line protection by the negative sequence current can be obtained. All of the types of line protections are RCS941-B and the setting values are 120A. According to the table 1 , there is no influence on the relay starting elements of protection for lines, because of just little negative sequence current caused by the traction loads.

\subsection{Study of effects on bus protection}

Bus protection is an important protection measure to ensure the safe and stable operation of power network, and its security, rapidity, reliability and sensitivity have a critical impact on the whole regional power grid. The current differential protection is usually taken as the main protection of the bus protection. In order to prevent the unreliable operation of the differential protection caused by the TA disconnection, the method of using compound voltage to lock bus differential protection is widely adopted. Typically, only when at least one of the conditions as follows is met, does the compound voltage lockoutopen.

Low voltage criterion:

$$
U_{\phi}<U_{d z}
$$

Negative sequence voltage criterion:

$$
U_{2}>U_{2 d z}
$$

Where $U_{\phi}$ is the phase voltage (or phase-to-phase voltage), $U_{2}$ is the negative sequence voltage, $U_{d z}, U_{2 d z}$ are the setting value.

Negative sequence voltage can be generated by the negative sequence current injected by the Electrified Railway. If the negative sequence voltage exceeds the setting value, it will cause the error opening of the bus differential protection. The result of the error opening of the compound voltage lockout element is that if the TA disconnection occurs during the opening period of the bus differential protection, the false operation of the differential protection can be caused. Therefore, it is needed to avoid the influence of the Electrified Railway from the setting value.

In the model of figure 1, the bus named no. 1 area 110 is installed bus protection, and the type of the protection is RCS915. The setting value of the bus differential negative sequence voltage criterion is $6 \mathrm{~V}$. From the table 2, it is obvious that the magnitude of the negative sequence voltage of the bus named no. 1 area 110 is $143 \mathrm{~V}$ which converted to the second side is $0.225 \mathrm{~V}$. It can be seen from the calculation that the negative sequence voltage is small, and it will not cause the error of the differential protection. It can be known that the negative sequence voltage caused by the negative sequence current of the Electrified Railway is not enough to cause the malfunction of the bus protection.

\subsection{Study of effects on transformer protection}

The second harmonic escapement in generator protection is according that the inrush current contains a large number of second harmonic current, when detecting the content of the second harmonic current is larger than the setting value the differential relay will be locked to prevent mis-operation caused by inrush current. The second harmonic escapement whose setting value is $15 \%$ is installed in all of the transformers in the model. From table 3 and table 4 the conclusion can be drawn that during the steady state failure, second harmonic current are much lower than the setting value to effect the transformer protection and the no. 1 area closest to the harmonic source whose differential protection is not affected by the harmonic current of traction load, furthermore, the other areas are not affected by it. 


\subsection{Study of effects on generator protection}

The rotor of generator will suffer injury, or even be destroyed if the negative sequence current flowing in the stator windings exceeds a certain value. Therefore, the long-term susceptive negative sequence current limit expressed by $I_{2 \infty}$ which is one of the setting bases of the negative current protection should be determined by the characteristics of the material and structure of the rotor. When the negative sequence current is more than $I_{2 \infty}$, the protective device should act and sent out sound and light signals reliably to deal with the fault in a timely manner. When the duration reaches a specified value, and the negative sequence current has not been eliminated, it should operate to remove the generator to prevent it from damaging $[8,9]$.

The time limited negative sequence overload protection will operate to remove the generator, when the formula (3) is met.

$$
\left.\begin{array}{c}
I_{2} \geq I_{2 o p} \\
t \geq t_{2 o p}
\end{array}\right\}
$$

In the formula (6), $I_{2}$ — The negative sequence current of generator stator windings (A);

$I_{2 o p}$ - The setting value of time limited rotor surface negative sequence overload protection of the generator $(\mathrm{A})$;

$t$ - The time of duration of the actioncondition of the time limited rotor surface negative sequence overload protection of the generator(s);

$t_{2 o p}$ - The setting value of the action time of the time limited rotor surface negative sequence over load protection of the generator(s)[10].

According to the relay protection setting notice of the no.6 area, the setting value of the time limited negative sequence overload protection of the two generators is $I_{o p}$ for $0.34 \mathrm{~A}$ and the CT ratio is $1200 / 1$. It is converted to primary side for 408A. From the table 5, the results can be reached that the time limited negative sequence overload protections of the two generators are not affected by the negative current because the setting value of the negative sequence current is less than 408A. It can be known that the negative sequence current caused by the Electrified Railway has no effect on the generator protection.

\section{Conclusions}

Firstly, the propagation characteristics of the harmonic and negative sequence current in the common power net are studied, and then the effects on the actions of power relay protection including line protection, bus protection, transformer protection and generator protection by the power quality caused by electrified railways are researched. The harmonic mainly affect the second harmonic escapement criteria of protection for transformers and the negative sequence component mainly affect the criterion of starting of protection for lines, the criterion of bus differential protection and the negative sequence overload protection for generator, which provides reference for the power grid planning. In addition, the influence on transformer protection and line protection by the power impact caused by traction locomotives should be studied in the future research.

\section{References}

1. Chen Minwu, Gong Yansheng, Li Qunzhan, et al. Assessment of Power Quality of Electrified Railway and the Research on the New Control Scheme. J. Power System Protection and Control 
40, 141 (2012)

2. Li Qionglin, Liu Shuming, Yu Xiaopeng, et al. Study on the impact of the $300 \mathrm{~km} / \mathrm{h}$ series high-speed special railway on the grid power quality. J. Power System Protection and Control 39, 78 (2011)

3. Zheng Aixia, Yuan Xiaodong, Li Qun. Harmonic analysis based on ETAP for Shanghai-Nanjing intercity railroad. J. Electric Power Automation Equipment 31, 108 (2011)

4. Jia Shanjie, Zhao Yishu, Gong Bing, et al. Influence of Jiao-ji electric railway to power quality of shandonggrid. J. Power System Technology 30, 11(2006)

5. Pee-Chin T, Poh C L., Holmes D G. Optimal impedance termination of 25-kV electrified railway systems for improved power quality. J. IEEE Trans. on Power Delivery 20, 1703 (2005)

6. Qian Hai. Discussion of $220 \mathrm{kV}$ line-protection operation in Ha-Da electrified railway road. J. Electric Power Automation Equipment 32, 68 (2002)

7. Guo Lei, Li Qunzhan, Xu Yinglei. Study on harmonic resonance of traction line in electrified high-speed traction system. C.//International Conference on Sustainable Power Generation and Supply. Nanjing: UK-China Network of Clean Energy Research (2009)

8. Gao Ran, Xu Yonghai, Xia Ruihua. Analysis of the operation of the generator negative current protection impacted on by the electric railway loading. J. Power System Protection and Control 37,41 (2009)

9. Zhou Xingbo, Han Mingxiao, Wang Zhichun, et al. Assessment on impact of negative-sequence component on nearby generators due to grid-connected traction load of electrified railway. J. Power System Technology 37, 3497 (2013)

10. Gao Ran. Research of effects on generator protection by harmonics and negative sequence of electric railway. D. Beijing: North China Electric Power University (2009)

11. Schellenberg A, Rosehart W, Aguado J. Introduction to cumulant based probabilistic optimal power flow. J. IEEE Transon Power Systems 20, 1184 (2005)

12. Yu Guangzheng, Lin Tao, Xu Xialing, et al. An algorithm based on $2 m+1$ point estimate method for harmonic probabilistic load flow calculation of power systems incorporating wind power[J]. Power System Technology 39, 3260 (2015) 